\title{
Chemoselective hydrogenation of arenes by PVP supported Rh nanoparticles
}

Ibrahim, Mahmoud; Poreddy, Raju; Philippot, Karine; Riisager, Anders; Garcia-Suarez, Eduardo J.

Published in:

Dalton Transactions

Link to article, DOI:

10.1039/C6DT03668F

Publication date:

2016

Document Version

Early version, also known as pre-print

Link back to DTU Orbit

Citation (APA):

Ibrahim, M., Poreddy, R., Philippot, K., Riisager, A., \& Garcia-Suarez, E. J. (2016). Chemoselective hydrogenation of arenes by PVP supported Rh nanoparticles. Dalton Transactions, 45, 19368-19373. https://doi.org/10.1039/C6DT03668F

\section{General rights}

Copyright and moral rights for the publications made accessible in the public portal are retained by the authors and/or other copyright owners and it is a condition of accessing publications that users recognise and abide by the legal requirements associated with these rights.

- Users may download and print one copy of any publication from the public portal for the purpose of private study or research.

- You may not further distribute the material or use it for any profit-making activity or commercial gain

- You may freely distribute the URL identifying the publication in the public portal 


\section{Dalton Transactions}

1

\section{Chemoselective hydrogenation of arenes by PVP supported Rh nanoparticles}

Mahmoud Ibrahim, Raju Poreddy, Karine Philippot,* Anders Riisager* and Eduardo J. Garcia-Suarez*

Polyvinyl pyrrolidone-stabilized Rh nanoparticles (RhNPs/PVP) of ca. $2.2 \mathrm{~nm}$ in size were prepared by the hydrogenation of an organometallic complex

$\left[\mathrm{Rh}\left(\eta^{3}-\mathrm{C}_{3} \mathrm{H}_{5}\right)_{3}\right]$ in the presence of PVP and evaluated as a catalyst in the hydrogenation of a series of arene substrates

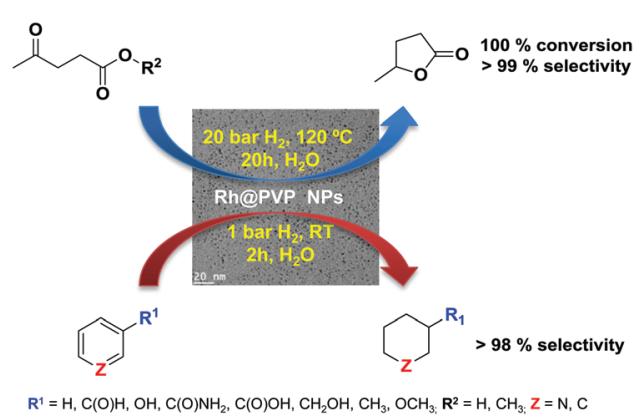

Please check this proof carefully. Our staff will not read it in detail after you have returned it.

Translation errors between word-processor files and typesetting systems can occur so the whole proof needs to be read. Please pay particular attention to: tabulated material; equations; numerical data; figures and graphics; and references. If you have not already indicated the corresponding author(s) please mark their name(s) with an asterisk. Please e-mail a list of corrections or the PDF with electronic notes attached - do not change the text within the PDF file or send a revised manuscript. Corrections at this stage should be minor and not involve extensive changes. All corrections must be sent at the same time.

Please bear in mind that minor layout improvements, e.g. in line breaking, table widths and graphic placement, are routinely applied to the final version.

We will publish articles on the web as soon as possible after receiving your corrections; no late corrections will be made.

Please return your final corrections, where possible within $\mathbf{4 8}$ hours of receipt, by e-mail to: dalton@rsc.org 


\section{Queries for the attention of the authors}

\section{Journal: Dalton Transactions}

Paper: c6dt03668f

\section{Title: Chemoselective hydrogenation of arenes by PVP supported Rh nanoparticles}

Editor's queries are marked like this [Q1, Q2,...], and for your convenience line numbers are indicated like this $[5,10,15, \ldots]$.

Please ensure that all queries are answered when returning your proof corrections so that publication of your article is not delayed.

\begin{tabular}{|c|c|c|}
\hline $\begin{array}{l}\text { Query } \\
\text { Reference }\end{array}$ & Query & Remarks \\
\hline Q1 & $\begin{array}{l}\text { For your information: You can cite this article before you } \\
\text { receive notification of the page numbers by using the following } \\
\text { format: (authors), Dalton Trans., (year), DOI: 10.1039/ } \\
\text { c6dt03668f. }\end{array}$ & \\
\hline Q2 & $\begin{array}{l}\text { Please carefully check the spelling of all author names. This is } \\
\text { important for the correct indexing and future citation of your } \\
\text { article. No late corrections can be made. }\end{array}$ & \\
\hline Q3 & $\begin{array}{l}\text { Please check that the inserted Graphical Abstract text is } \\
\text { suitable. Please ensure that the text fits between the two } \\
\text { horizontal lines. }\end{array}$ & \\
\hline Q4 & $\begin{array}{l}\text { The sentence beginning "The PVP matrix..." has been altered } \\
\text { for clarity, please check that the meaning is correct. }\end{array}$ & \\
\hline Q5 & Ref. 15: Please provide the last name for the 7th author. & \\
\hline Q6 & Please check that ref. 28 has been displayed correctly. & \\
\hline
\end{tabular}




\section{Dalton \\ Transactions}

Q1

Received 21st September 2016, Accepted 9th November 2016

DOI: $10.1039 / c 6 d t 03668 f$

www.rsc.org/dalton

\section{Chemoselective hydrogenation of arenes by PVP supported Rh nanoparticles}

\author{
Mahmoud Ibrahim, ${ }^{a, b}$ Raju Poreddy, ${ }^{c}$ Karine Philippot, ${ }^{\star a, b}$ Anders Riisager ${ }^{\star c}$ and \\ Eduardo J. Garcia-Suarez ${ }^{*}$
}

Polyvinyl pyrrolidone-stabilized Rh nanoparticles (RhNPs/PVP) of ca. $2.2 \mathrm{~nm}$ in size were prepared by the hydrogenation of an organometallic complex $\left[\mathrm{Rh}\left(\eta^{3}-\mathrm{C}_{3} \mathrm{H}_{5}\right)_{3}\right]$ in the presence of PVP and evaluated as a catalyst in the hydrogenation of a series of arene substrates as well as levulinic acid and methyl levulinate. The catalyst showed excellent activity and selectivity towards aromatic ring hydrogenation compared to other reported transition metal-based catalysts under mild reaction conditions (room temperature and 1 bar $\mathrm{H}_{2}$ ). Furthermore, it was shown to be a highly promising catalyst for the hydrogenation of levulinic acid and methyl levulinate in water leading to quantitative formation of the fuel additive $\gamma$-valerolactone under moderate reaction conditions compared to previously reported catalytic systems.

\section{Introduction}

The hydrogenation of aromatic $\mathrm{C}-\mathrm{C}$ double bonds to form cyclohexane derivatives is one of the most important reactions in both petrochemical and pharmaceutical industries. For instance, the chemoselective hydrogenation of benzoic acid to cyclohexane carboxylic acid ${ }^{1}$ is a crucial step in the fiber industry for the synthesis of $\varepsilon$-caprolactam from toluene in the Snia Viscosa process (developed by SNIA S.p.A., Italy). ${ }^{2}$ Furthermore, cyclohexane carboxylic acid is a key intermediate in the synthesis of pharmaceuticals in high demand such as praziquantel and ansatrienin (Fig. 1). ${ }^{3-5}$

The high relevance of benzoic acid hydrogenation in both bulk and fine chemical industries has attracted a lot of attention from the scientific community to develop catalysts for the chemoselective hydrogenation of benzoic acid to cyclohexane
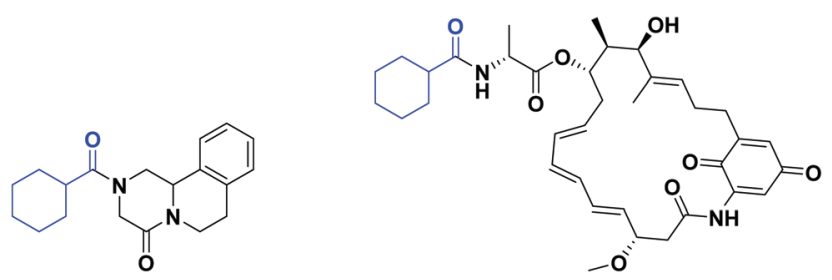

Fig. 1 Praziquantel (left) and ansatrienin (right).

${ }^{a}$ CNRS, LCC (Laboratoire de Chimie de Coordination), 205 Route de Narbonne, BP44099, 31077 Toulouse Cedex 4, France. E-mail: karine.philippot@lcc-toulouse.fr ${ }^{b}$ Université de Toulouse, UPS, INPT, 31077 Toulouse Cedex 4, France ${ }^{c}$ Centre for Catalysis and Sustainable Chemistry, Department of Chemistry, Technical University of Denmark, DK-2800 Kgs. Lyngby, Denmark.E-mail: edgar@kemi.dtu.dk carboxylic acid. However, hydrogenation of aromatic $\mathrm{C}-\mathrm{C}$ double bonds, compared to olefinic $\mathrm{C}-\mathrm{C}$ double bonds, is a very challenging transformation since it generally requires severe reaction conditions. Moreover, a selective catalyst is needed which only hydrogenates the aromatic ring while keeping other functional groups present in the molecule intact. Noble transition metal catalysts, either homogeneous or heterogeneous systems, including $\mathrm{Ru}-\mathrm{Pt}, \mathrm{Rh} / \mathrm{C}, \mathrm{Pd} / \mathrm{C}$, and $\mathrm{Pd}-\mathrm{Ru}$ have been extensively studied for arene hydrogenation and generally found to exhibit high activities. ${ }^{2,6-9}$ Among them, $\mathrm{Rh} / \mathrm{AC}$ (AC = activated carbon) and $\mathrm{Pd} / \mathrm{AC}$ catalysts show superior catalytic activity compared to other supported transition metal catalysts. ${ }^{10} \mathrm{Pd} / \mathrm{AC}$ are traditionally used for $\varepsilon$-caprolactam production in the chemical fiber industry ${ }^{11}$ and for terephthalic acid refining in the polyester industry. ${ }^{12}$

It is worth pointing out that the process of benzoic acid to cyclohexane carboxylic acid hydrogenation with Pd/AC catalysts suffers from a number of limitations, i.e. high temperature $\left(150{ }^{\circ} \mathrm{C}\right.$ ) and high $\mathrm{H}_{2}$ pressure (150 bar) conditions as well as excessive catalyst consumption due to its fast deactivation. ${ }^{13}$ Tsung et al. have recently reported that Pt nanocrystals are catalytically active in the hydrogenation of pyrrole to $n$-butylamine and that both the activity and the selectivity strongly depend on the shape and size of Pt nanocrystals. ${ }^{14}$ A similar behavior was observed by $\mathrm{Hu}$ et al. using Pd nanocrystals in citral and cyclohexene hydrogenation. ${ }^{15}$ Yoon et al. investigated a bimetallic Rh-Pd/CNT (CNT = carbon nanotube) catalyst for benzene hydrogenation which displayed a much higher activity compared to Rh/CNT or Pd/CNT monometallic catalysts alone. The superior activity was attributed to a synergistic effect between $\mathrm{Rh}$ and $\mathrm{Pd}$, but the reaction system required elevated pressure (10 bar) in order to observe sufficient activity. ${ }^{16}$ 
1 Metal nanoparticle catalysis has progressed significantly during the last 25 years. ${ }^{17}$ However, a major drawback often reported when using nanoparticles in solution catalysis is the drop in catalytic activity and selectivity associated with particle agglomeration due to a lack of stability with time and/or reaction conditions. Accordingly, intensive research has been focused on developing approaches to increase particle stability and improve catalytic performance. In particular, numerous supports and/or stabilizers (polymers or ligands) that could limit nanoparticle evolution during their application as catalysts in solution have been studied. Among polymers employed as stabilizers of metal nanoparticles, polyvinyl pyrrolidone (PVP) efficiently controls the particle growth and contributes to obtain a uniform metal nanoparticle dispersion in the polymer matrix. For these reasons, PVP-stabilized Rh nanoparticles (RhNPs) have attracted attention for arene hydrogenation in both ionic liquids and water as reaction media at relatively low temperatures. ${ }^{18,19}$

In this work, we report results on the mild hydrogenation of benzoic acid and its derivative benzamide to cyclohexane carboxylic acid and cyclohexane carboxamide at room temperature and atmospheric $\mathrm{H}_{2}$ pressure with a RhNP/PVP nanocatalyst using water as a green and eco-friendly solvent. Furthermore, the RhNP/PVP nanocatalyst has been evaluated in aqueous phase hydrogenation of levulinic acid and its methyl ester to $\gamma$-valerolactone.

\section{Experimental part}

\section{Materials}

All manipulations were carried out under an inert atmosphere using standard Schlenk techniques or in a glove-box if not otherwise stated. Tetrahydrofuran (THF) and n-pentane were purchased from Sigma-Aldrich, purified by column-filtration and degassed by means of three freeze-pump-thaw cycles before use. Other solvents and/or reagents were purchased from Sigma-Aldrich and used without further purification except for PVP that was dried under vacuum over $\mathrm{P}_{2} \mathrm{O}_{5}$ at $80{ }^{\circ} \mathrm{C}$ for 3 days prior to use. The rhodium precursor $\left[\mathrm{Rh}\left(\eta^{3}-\mathrm{C}_{3} \mathrm{H}_{5}\right)_{3}\right]$ was synthesized from $\mathrm{RhCl}_{3} \cdot 3 \mathrm{H}_{2} \mathrm{O}$ (Johnson Matthey) and $\mathrm{CH}_{2}=\mathrm{CHCH}_{2} \mathrm{MgCl}$ (Sigma-Aldrich; solution 2.0 M in THF) following a published preparation method. ${ }^{20}$ Hydrogen gas (Alphagaz) was purchased from Air Liquide.

\section{Synthesis of RhNPs/PVP}

The $\left[\mathrm{Rh}\left(\eta^{3}-\mathrm{C}_{3} \mathrm{H}_{5}\right)_{3}\right]$ metal precursor $(150 \mathrm{mg}, 0.663 \mathrm{mmol})$ was placed in a Fisher-Porter bottle and left under vacuum for $30 \mathrm{~min}$. The Fisher-Porter bottle was then cooled to $-80{ }^{\circ} \mathrm{C}$ and a THF solution $(150 \mathrm{~mL})$ containing $680 \mathrm{mg}$ of $\mathrm{PVP}\left(M_{\mathrm{W}}=\right.$ $40000 \mathrm{~g} \mathrm{~mol}^{-1}$ ) was added to the rhodium complex leading to a yellow solution. The reaction mixture was then allowed to warm up to room temperature before pressurization with $\mathrm{H}_{2}$ (3 bar). After $10 \mathrm{~min}$, the yellow solution turned into a black colloidal solution indicating the formation of NPs. The solution was left for stirring under a $\mathrm{H}_{2}$ atmosphere for an additional $16 \mathrm{~h}$ to ensure complete decomposition of the metal precursor. Then excess of $\mathrm{H}_{2}$ was removed under vacuum and the colloidal solution was concentrated to $10 \mathrm{~mL}$ before addition of $n$-pentane in order to precipitate the RhNPs. The resulting RhNP/PVP solid was washed twice with $n$-pentane, filtered and dried under vacuum overnight and the crystalline dark grey powder obtained ( 600 mg) was kept under an inert atmosphere until use.

\section{Characterization of RhNPs/PVP}

TEM and HR-TEM analyses. Samples for transmission electron microscopy (TEM) and high resolution HR-TEM analyses were prepared by slow evaporation of a drop of the crude colloidal solution deposited onto a holey carbon-covered copper grid under argon (in glove-box). TEM and HR-TEM analyses were performed on a MET JEOL JEM 1400 microscope operating at $120 \mathrm{kV}$ and a JEOL JEM 2010 microscope working at $200 \mathrm{kV}$ with a resolution point of $2.5 \AA$ and equipped with an Energy-Dispersive X-ray (EDX; Noran) spectrometer, respectively. Enlarged micrographs were used for treatment with ImageJ software to obtain a statistical size distribution and the nanoparticle mean diameter. FFT treatments were carried out with Digital Micrograph Version 1.80.70 to determine the NP crystalline structure.

ICP-AES analyses. The Rh content of the RhNP/PVP catalyst was quantified by inductively coupled plasma atomic emission spectroscopy (ICP-AES) using a Thermo Scientific iCAP 6300 DUO spectrometer with a 3-channel, 12-roller pump and a 27.12 $\mathrm{MHz}$ solid state RF plasma generator. Mineralization of the RhNP/PVP sample was performed in aqua regia solution.

XPS analyses. X-ray photoelectron spectroscopy (XPS) data were acquired with a ThermoScientific system at room temperature using $\mathrm{Al}-\mathrm{K} \alpha$ radiation $(1484.6 \mathrm{eV})$ as the excitation X-ray source. During analysis the pressure in the chamber was maintained at $2 \times 10^{-10}$ mbar. The XPS measurements were then performed in the electron binding energy range corresponding to $\mathrm{Rh} 3 \mathrm{~d}$ excitations and $\mathrm{C}, \mathrm{N}$ and $\mathrm{O} 1 \mathrm{~s}$ excitations. All samples were measured twice and the reported values are the average of the two analyses.

\section{General hydrogenation procedure}

All reactions were performed in a $300 \mathrm{~mL}$ stainless steel high pressure autoclave equipped with an electrically heated jacket, a turbine stirrer with a variable speed magnetic driver and a liquid sampling line. In a typical reaction, the reactor was loaded with the substrate $(0.5 \mathrm{mmol})$, water $(50 \mathrm{~mL})$ and catalyst $(10 \mathrm{mg})$. Afterwards, the reactor was pressurized with $\mathrm{H}_{2}$ ( 4 bar) three times followed by evacuation to displace residual air in the reactor. The autoclave was then filled with $\mathrm{H}_{2}$ ( 1 or 10 bar), heated to the desired temperature and the reaction was initiated by stirring the mixture at $320 \mathrm{rpm}$. After the selected reaction time the autoclave was cooled down to room temperature. An aliquot of the reaction mixture was subsequently analyzed by gas chromatography (GC-FID) using a chromatograph (Agilent $6890 \mathrm{~N}$ ) equipped with an HP-5 capillary column (Agilent, J\&W, $30 \mathrm{~m} \times 320 \mu \mathrm{m}$ ). Gas chromato- 
graphy coupled to mass spectrometry (GC-MS) was also performed on Agilent 6850N equipment fitted with the same capillary column.

\section{Results and discussion}

\section{Characterization of RhNPs/PVP}

Rhodium nanoparticles stabilized by the PVP polymer (RhNPs/ PVP) were synthesized following the so-called "organometallic approach" previously developed by some of the authors. ${ }^{21,22}$ This method allows us to prepare well-controlled NPs that display interesting catalytic properties. ${ }^{23}$ The organometallic complex $\left[\mathrm{Rh}\left(\eta^{3}-\mathrm{C}_{3} \mathrm{H}_{5}\right)_{3}\right]$ was used as the rhodium source, and decomposed in THF solution at room temperature under a $\mathrm{H}_{2}$ atmosphere and mild conditions $\left(3\right.$ bar $\left.\mathrm{H}_{2}\right) .{ }^{24}$ The main advantage of this method is the formation of propane as the only byproduct, which is inert towards the metallic surface and can be easily removed, thus allowing to obtain uncoordinated metal NPs in the PVP stabilizing matrix. The PVP matrix retains NPs that are both soluble in organic solvents and water.

The RhNPs/PVP were characterized by electron microscopy at low (TEM) and high resolution (HR-TEM) coupled with energy-dispersive X-ray spectroscopy (EDX) techniques to determine the dispersion of the particles inside the PVP polymer and their mean diameter as well as the crystalline structure. TEM analysis performed on the crude colloidal solution confirmed the presence of small, spherical, and very welldispersed Rh NPs with a mean size of $c a .2 .2( \pm 0.9) \mathrm{nm}$. The particles were found to be homogeneous in shape with a quite narrow size distribution (Fig. 2a and c). HR-TEM analysis (Fig. 2b; [011] atomic planes) revealed well-crystallized NPs with a face centered cubic (fcc) packed structure as expected for metallic $\mathrm{Rh}(0)$. The EDX analysis showed a clear signal for elemental $\mathrm{Rh}$ as well as well-identified signals for $\mathrm{C}$ and $\mathrm{N}$ atoms from the PVP polymer that embeds the particles (Fig. 2d).

The oxidation state and the surrounding chemical environment of RhNPs/PVP were examined by X-ray photoelectron spectroscopy (XPS). Fig. 3a shows XPS spectra with the signals corresponding to $\mathrm{C}, \mathrm{N}$ and $\mathrm{O}$ from PVP used as a stabilizer and $\mathrm{Rh}$ (elemental survey). A signal found at about $200.5 \mathrm{eV}$ (Fig. 3a, inset) is attributed to contamination of $\mathrm{Cl}$ from the organometallic precursor. However, it is quite insignificant since it is only about $0.13 \%$ of the corresponding intensity compared to the $\mathrm{C} 1 \mathrm{~s}$ level signal. Fig. $3 \mathrm{~b}$ shows the $3 \mathrm{~d}$ core level XPS spectra for RhNPs/PVP. The lower binding energy signals at $307.8 \mathrm{eV}\left(3 \mathrm{~d}_{5 / 2}\right)$ and at about $311.9 \mathrm{eV}\left(3 \mathrm{~d}_{3 / 2}\right)$ confirm the metallic state of the Rh NPs. The higher binding energy peak at $313-315 \mathrm{eV}\left(3 \mathrm{~d}_{3 / 2}\right)$ suggests the presence of rhodium oxide species, and a comparison with earlier
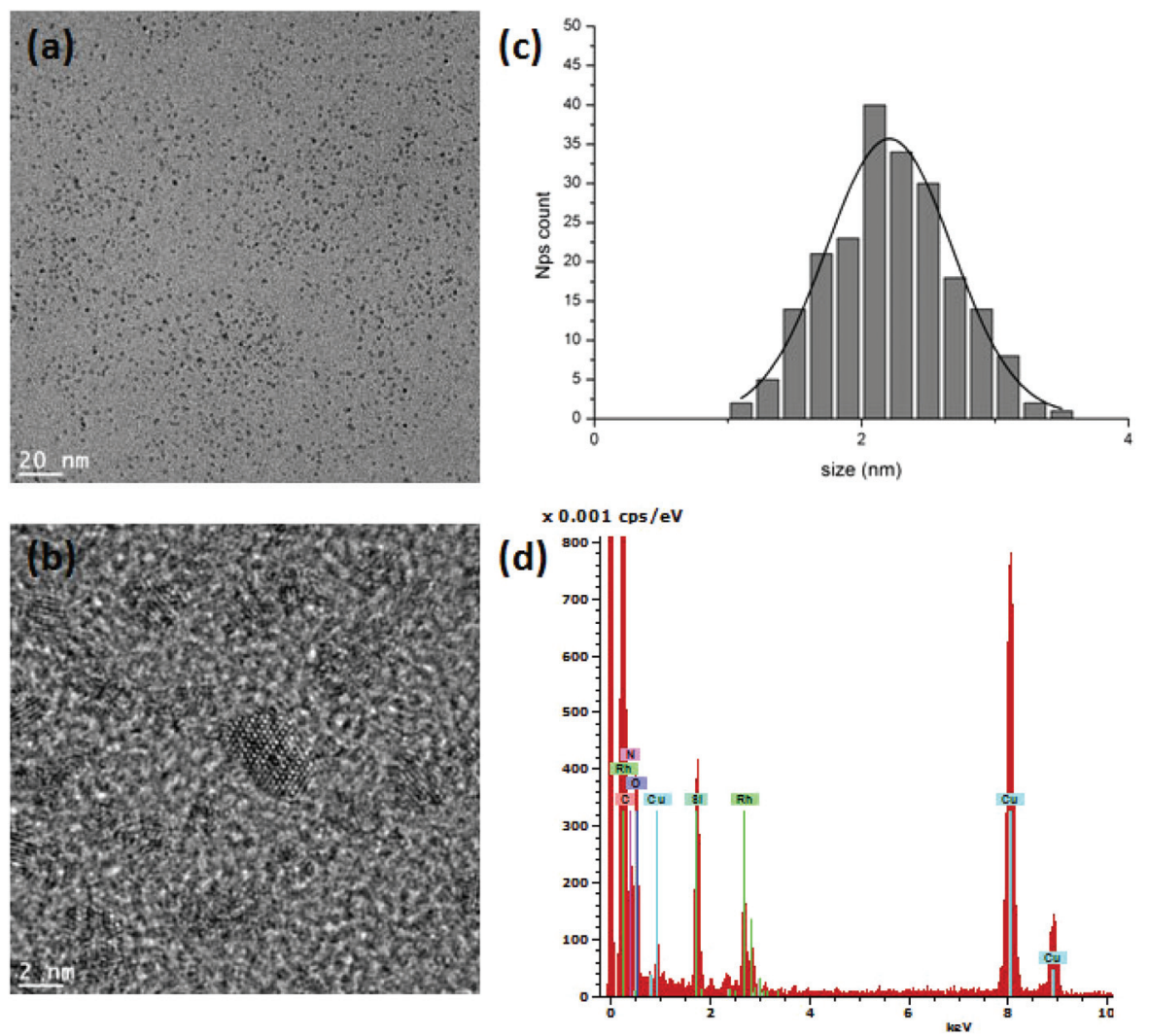

Fig. 2 (a) TEM and (b) HR-TEM images of the as-prepared RhNPs/PVP; (c) NP size distribution histogram; (d) EDX analysis spectrum. 


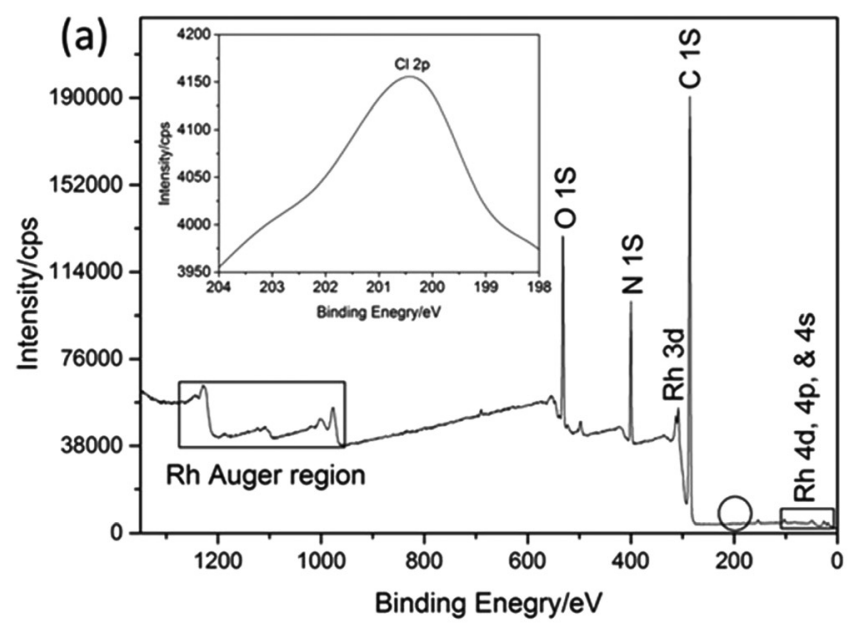

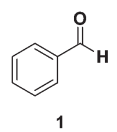
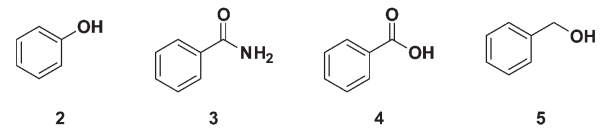

investigations is in agreement with $\mathrm{Rh}^{3+}$ species in $\mathrm{Rh}_{2} \mathrm{O}_{3}{ }^{25}$ The presence of such species can be attributed to partial oxidation during sample preparation and/or sample introduction to the spectrometer. However, even if such rhodium oxide species are present, they are likely to be reduced under the hydrogenation reaction conditions to $\mathrm{Rh}(0)$. A small signal is further detected at $304 \mathrm{eV}$ and attributed to the $3 \mathrm{~d}$ level with different chemical environments on the surface. The Rh metal content in the RhNPs/PVP was determined by ICP-AES to be equal to $7.37 \mathrm{wt} \%$.

\section{Selective hydrogenation of arenes with RhNPs/PVP}

Benzamide (3 in Fig. 4) was chosen as a first substrate for the optimization of the selective hydrogenation reaction conditions, because of its low price compared to benzoic acid. As the nature of the solvent (protic, aprotic, polar or apolar) is a well-known parameter influencing catalyst activity and selectivity in hydrogenation reactions, ${ }^{26}$ three different solvents were initially tested; $n$-hexane, methanol and water, for the benzamide hydrogenation to cyclohexane carboxamide under mild reaction conditions $\left(80^{\circ} \mathrm{C}, 1 \mathrm{bar}_{2}, 2 \mathrm{~h}\right.$ reaction time). Both conversion and selectivity were determined by GC and GC-MS analyses and are reported in Table 1 . Water, which has the least solubility of $\mathrm{H}_{2}$, gave a full conversion of benzamide and $100 \%$ selectivity towards the formation of cyclohexane carbox-
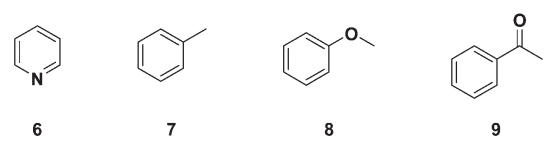

Fig. 4 Arene substrates examined for the selective hydrogenation with RhNPs/PVP.

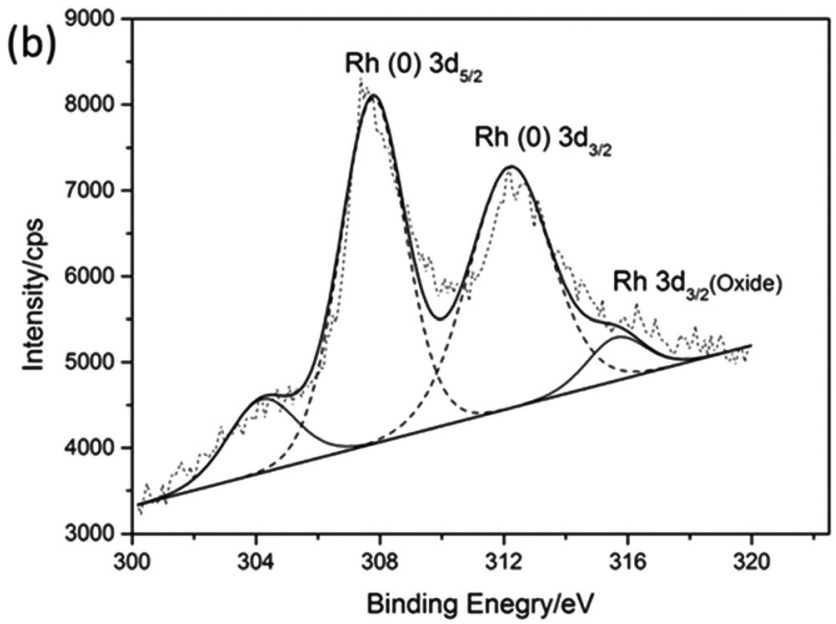

Fig. 3 (a) XPS spectra of the RhNPs/PVP; (inset) enlarged area of the Cl (2p) level; (b) $3 \mathrm{~d}$ core level XPS of the RhNPs/PVP.

amide (Table 1, entry 3 ), whereas $n$-hexane, and methanol with relatively high solubility of $\mathrm{H}_{2}$, were found to be much less effective; no more than 39 and $71 \%$ conversion were achieved for $n$-hexane and methanol, respectively (Table 1, entries 1 and 2). The study was then pursued with water as the reaction solvent to analyze the influence of temperature. At 40 and $25{ }^{\circ} \mathrm{C}$ (Table 1 entries 4 and 5) the Rh nanocatalyst displays the same high activity as at $80^{\circ} \mathrm{C}$, yielding full conversion of benzamide with $100 \%$ selectivity towards the desired cyclohexane carboxamide product. Furthermore, a control experiment with no catalyst was performed in order to ensure the indispensability of the catalyst for benzamide hydrogenation to cyclohexane carboxamide. As expected, no reaction product was achieved under the selected reaction conditions (Table 1 , entry 6).

After choosing the preferred reaction conditions regarding solvent and temperature (water and $25{ }^{\circ} \mathrm{C}$ ) the catalytic performance of the RhNP/PVP catalyst was evaluated for hydrogenation of alternative substrates. A series of eight other arene substrates containing diverse electron donating (EDG) or electron withdrawing (EWG) groups were selected (Fig. 4), and the obtained results are collected in Table 2 .

The RhNP/PVP catalyst showed excellent activity with all of the tested arene substrates resulting in conversions in the range of $74-100 \%$ and selectivity $>97 \%$ to the desired ring hydrogenated products except for acetophenone 9 (Table 2, entries 1-9). Instead, the product selectivity of cyclohexyl methyl ketone from 9 was only $20 \%$ and 1-phenylethanol (keto group hydrogenation) was observed as the major product, thus indicating preferential reduction of the carbonyl group, instead of ring hydrogenation, for this substrate. ${ }^{27}$ Notably, the oxo group contained in benzamide 3 and benzoic acid 4 was not reduced under the applied reaction conditions. These observations corroborate with previously reported results with Rh NPs stabilized on carbon nanofibers (CNF) under similar reaction conditions. ${ }^{28}$ As shown in Table 2, no clear differences were found under the applied reaction conditions in the 


\begin{tabular}{lllccc}
\hline Entry & Solvent & Temperature $\left({ }^{\circ} \mathrm{C}\right)$ & Conversion $(\%)$ & Selectivity $^{b}(\%)$ & $>99$ \\
\hline 1 & $n$-Hexane & 80 & 39 & $>99$ & 13.9 \\
2 & Methanol & 80 & 71 & $>99$ & 25.4 \\
3 & Water & 80 & 100 & $>99$ & 35.7 \\
4 & Water & 40 & 100 & $>99$ & 35.7 \\
5 & Water & 25 & 100 & 0 & 0
\end{tabular}

${ }^{a}$ Reaction conditions: $0.5 \mathrm{mmol}$ substrate, $10 \mathrm{mg}$ RhNP/PVP catalyst (7.36 wt\% Rh), $1.4 \mathrm{~mol} \%$ substrate, $50 \mathrm{~mL}$ solvent, 2 h, $320 \mathrm{rpm}, 1 \mathrm{bar} \mathrm{H}_{2}$. ${ }^{b}$ Selectivity to cyclohexane carboxamide. ${ }^{c}$ Calculated as mol cyclohexane carboxamide per mol Rh per hour. ${ }^{d}$ No catalyst.

Table 2 Hydrogenation of alternative arenes ${ }^{a}$ hexane carboxamide per mol Rh per hour.

\begin{tabular}{llllll}
\hline Entry & Substrate & $\begin{array}{l}\text { Conversion } \\
(\%)\end{array}$ & $\begin{array}{l}\text { Yield } \\
(\%)\end{array}$ & $\begin{array}{l}\text { Selectivity } \\
(\%)\end{array}$ & $\begin{array}{l}\mathrm{TOF}^{c} \\
\left(\mathrm{~h}^{-1}\right)\end{array}$ \\
\hline 1 & $\mathbf{1}$ & 74 & 73 & $>98$ & 26.4 \\
2 & $\mathbf{2}$ & 100 & 99 & $>99$ & 35.7 \\
3 & $\mathbf{3}$ & 100 & 97 & $>97$ & 35.7 \\
4 & $\mathbf{4}$ & 100 & 99 & $>99$ & 35.7 \\
5 & $\mathbf{5}$ & 93 & 92 & $>98$ & 33.2 \\
6 & $\mathbf{6}$ & 86 & 85 & $>98$ & 30.6 \\
7 & 7 & 100 & 99 & $>99$ & 35.7 \\
8 & $\mathbf{8}$ & 100 & 99 & $>99$ & 35.7 \\
9 & $\mathbf{9}$ & 100 & 20 & 20 & 35.7
\end{tabular}

${ }^{a}$ Reaction conditions: $0.5 \mathrm{mmol}$ substrate, $10 \mathrm{mg}$ RhNPs/PVP (7.36 wt\% Rh), $1.4 \mathrm{~mol} \%, 50 \mathrm{~mL}$ solvent, $25{ }^{\circ} \mathrm{C}, 2 \mathrm{~h}, 320 \mathrm{rpm}, 1$ bar $\mathrm{H}_{2}$. ${ }^{b}$ Selectivity to ring hydrogenation product. ${ }^{c}$ Calculated as mol cyclo-

catalytic hydrogenation of the arene substrates despite their different EDG or EWG. It has been proposed that EDG can facilitate faster hydrogenation as the result of a much stronger adsorption of the substrates on the metal surface. However, stronger adsorption can also be detrimental because of an increase of the hydrogenation energy barrier due to $\pi$-complexation of the aromatic ring..$^{28,29}$ Thus, these opposing effects probably make the effect of EDG or EWG unclear. ${ }^{30}$ In terms of TOF the catalytic performance of the prepared RhNP/ PVP catalyst is similar to the results obtained by Barbaro and co-workers with resin-supported RhNP catalysts under mild reaction conditions ( 1 bar and RT). ${ }^{31}$ Other RhNP-based catalytic systems have been reported to be more active in the hydrogenation of arenes than the one presented in this work, but usually the reaction conditions are more harsh in terms of temperature $\left(>60{ }^{\circ} \mathrm{C}\right)$ and $\mathrm{H}_{2}$ pressure ( $>10$ bar). Moreover, the present work uses water as the solvent making the overall process greener than other reported catalytic systems. ${ }^{31-33}$

Encouraged by the good performance of the RhNP/PVP catalyst in the selective hydrogenation of arenes, the hydrogenation of levulinic acid and methyl levulinate was further explored as a plausible route to obtain $\gamma$-valerolactone from biomass (Scheme 1). The reaction conditions were selected on the basis of our recently developed catalytic system with Au core and Pt shell NPs stabilized on graphitized carbon black (Au@Pt/G-CB). ${ }^{28,34}$ Thus, the reactions were performed at $120^{\circ} \mathrm{C}$ under 20 bar of $\mathrm{H}_{2}$ for $20 \mathrm{~h}$ in water as a solvent.<smiles>[R]OC(=O)CCC(C)=O</smiles>

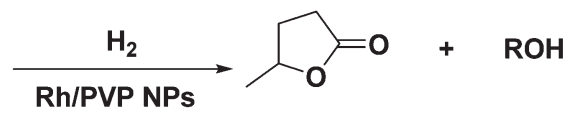

\section{$\mathbf{R}=\mathbf{H}$ or $\mathrm{CH}_{3}$}

Scheme 1 Hydrogenation of levulinic acid and methyl levulinate.

In both of the examined reactions $100 \%$ conversion and $>99 \%$ selectivity to $\gamma$-valerolactone were achieved with the RhNP/ PVP catalyst. These initial results are highly promising since significantly more harsh reaction conditions $\left(200{ }^{\circ} \mathrm{C}, 30-40\right.$ bar $\mathrm{H}_{2}$ ) are generally reported in the literature for these reactions to achieve similar yields of $\gamma$-valerolactone with catalysts containing transition metals like Pt, $\mathrm{Ru}$ and Rh. ${ }^{29,30,35,36}$ More detailed exploration of the $\gamma$-valerolactone formation from methyl levulinate and derivatives will be the subject of future work.

\section{Conclusions}

Well-defined PVP-stabilized Rh nanoparticles of ca. $2.2 \mathrm{~nm}$ in size were obtained via the organometallic method, namely by hydrogenation of the organometallic complex $\left[\mathrm{Rh}\left(\eta^{3}-\mathrm{C}_{3} \mathrm{H}_{5}\right)_{3}\right]$ in the presence of PVP, and then evaluated as a catalyst in the hydrogenation of a series of arene substrates. The RhNP/PVP catalyst showed excellent activity and selectivity towards aromatic ring hydrogenation compared to other reported transition metalbased catalysts at room temperature and 1 bar $\mathrm{H}_{2}$, except for acetophenone where 1-phenylethanol was formed as the major product. In addition, the prepared RhNP/PVP nanomaterial was shown to be a highly promising catalyst for the hydrogenation of levulinic acid and methyl levulinate in water, leading to quantitative formation of the fuel additive $\gamma$-valerolactone under moderate reaction conditions in contrast to previously reported catalytic systems. Recycling tests of the RhNP/PVP catalyst are currently under investigation to validate its long-term stability.

\section{Acknowledgements}

The authors thank V. Collière at the "Centre de microcaractérisation Raymond Castaing - UMS 3623 in 
Toulouse" for HR-TEM analysis. CNRS and UPS-Université de Toulouse are acknowledged for financial support and a MESR PhD fellowship (M. Ibrahim). The UNIK research initiative Catalysis for Sustainable Energy is also acknowledged for financial support of a PhD fellowship (R. Poreddy).

\section{Notes and references}

1 M. I. Temkin, V. Y. Konyukhov and N. V. Kul'kova, J. Res. Inst. Catal., 1980, 28, 363-370.

$2 \mathrm{H}$. Weissermel and H. J. Arpe, Industrial organic chemistry, VCH, Weinheim, 3rd edn, 1997, pp. 256-257.

3 S. M. Patton, T. A. Cropp and K. Reynolds, Biochemistry, 2000, 39, 7595-7604.

4 H. Shinkai, M. Nishikawa, Y. Sato, K. Toi, I. Kumashiro, Y. Seto, M. Fukuma, K. Dan and S. Toyoshima, J. Med. Chem., 1989, 32, 1436-1441.

5 B. S. Moore, H. Cho, R. Casati, E. Kennedy, K. A. Reynolds, U. Mocek, J. M. Beale and H. G. Floss, J. Am. Chem. Soc., 1993, 115, 5254-5266.

6 J. M. Thomas, B. F. Johnson, R. Raja, G. Sankar and P. A. Midgley, Acc. Chem. Res., 2003, 36, 20-30.

7 H. J. Wang and F. Y. Zhao, Int. J. Mol. Sci., 2007, 8, 628-634.

8 B. N. Zong, X. X. Zhang and M. H. Qiao, AIChE J., 2009, 55, 192-197.

9 R. Raja, T. Khimyak, J. M. Thomas, S. Hermans and B. F. Johnson, Angew. Chem., Int. Ed., 2001, 40, 4638-4642.

10 R. L. Augustine, Heterogeneous Catalysis for the Synthetic Chemist, Marcel Dekker, New York, 1996.

11 J. C. Kou, X. X. Zhang and B. N. Zong, Chem. Ind. Eng. Prog., 2002, 21, 741-744.

12 N. Pernicone, M. Cerboni, G. Prelazzi, F. Pinna and G. Fagherazzi, Catal. Today, 1998, 44, 129-135.

13 (a) SNIA VISCOSA, Italy Patent, IE967918, 1964; (b) SNIA VISCOSA, Italy Patent, IE1019795, 1966; (c) SNIA VISCOSA, Italy Patent, IE1122162, 1968.

14 C.-K. Tsung, J. N. Kuhn, W. Huang, C. Aliaga, L.-I. Hung, G. A. Somorjai and P. Yang, J. Am. Chem. Soc., 2009, 131, 5816-5822.

15 B. Hu, K. Ding, T. Wu, X. Zhou, H. Fan, T. Jiang, Q. and B. Han, Chem. Commun., 2010, 46, 8552-8554.

16 B. Yoon, H.-B. Pan and C.-M. Wai, J. Phys. Chem. C, 2009, 113, 1520-1525.

17 (a) D. Astruc, Nanoparticles and Catalysis, Wiley-VCH, 2008; (b) V. Polshettiwar, in Nanomaterials in Catalysis, ed. P. Serp and K. Philippot, 2013; (c) E. Kemnitz and V. Parvulescu, New Materials for Catalytic Applications, Elsevier, 2016.
18 X. Yang, N. Yan, Z. Fei, R. M. Crespo-Quesada, 1 G. Laurenczy, L. Kiwi-Minsker, Y. Kou, Y. Li and P. J. Dyson, Inorg. Chem., 2008, 47, 7444-7446.

19 N. Yan, Y. Yuan and P. J. Dyson, Chem. Commun., 2011, 47, 2529-2531.

20 J. Powell and B. L. Shaw, Chem. Commun., 1966, 323-325.

21 C. Amiens, B. Chaudret, D. Ciuculescu-Pradines, V. Collière, K. Fajerwerg, P. Fau, M. Kahn, A. Maisonnat and K. Philippot, New J. Chem., 2013, 37, 3374-3401.

22 C. Amiens, D. Ciuculescu-Pradines and K. Philippot, Coord. Chem. Rev., 2016, 308, 409-432.

23 S. Kinayyigit and K. Philippot, Organometallic Approach for the Synthesis of Noble Metal Nanoparticles: Towards Application in Colloidal and Supported Nanocatalysis, in Metal Nanoparticles for Catalysis: Advances and Applications, ed. T. Tao, RSC, 2014, ch. 4, pp. 47-82.

24 M. Ibrahim, Functionalization of Metal Nanoparticles for Application in Catalysis, PhD Thesis, UPS-Toulouse, 2016.

25 (a) M. Peuckert, Surf. Sci., 1984, 141, 500-514; (b) T. L. Barr, J. Phys. Chem., 1978, 82, 1801-1810.

26 H. Takagi, T. Isoda, K. Kusakabe and S. Morooka, Energy Fuels, 1999, 13, 1191-1196.

27 J. L. Castelbou, E. Bres-Femenia, P. Blondeau, B. Chaudret, S. Castillon, C. Claver and C. Godard, ChemCatChem, 2014, 6, 3160-3168.

28 (a) J. A. Anderson, A. Athawale, F. E. Imrie, F.-M. Kenna, A. McMcCue, D. Molyneux, K. Power, M. Shand and R. P. K. Wells, J. Catal., 2010, 270, 9-15; (b) J. Schulz, A. Roucoux and H. Patin, Chem. - Eur. J., 2000, 6, 618-624.

29 M. Zahmakiran, Y. Romanleshkov and Y. Zhang, Langmuir, 2012, 28, 60-64.

30 F. Lu, J. Liu and J. Xu, J. Mol. Catal. A: Chem., 2007, 271, 6-13.

31 C. Moreno-Madorran, F. Liguori, E. Mercade, C. Godard, C. Claver and P. Barbaro, Catal. Sci. Technol., 2015, 5, 37623772 .

32 A. Sanchez, M. Fang, A. Ahmed and R. A. Sanchez-Delgado, Appl. Catal., A, 2014, 477, 117-124.

33 L. Huang, P. Luo, W. Pei, X. Liu, Y. Wang, J. Wang, W. Xing and J. Huan, Adv. Synth. Catal., 2012, 354, 26892694.

34 C. Engelbrekt, N. Seselj, R. Poreddy, A. Riisager, J. Ulstrup and J. Zhnag, J. Mater. Chem. A, 2016, 4, 3278-3286.

35 K. Kon, W. Onodera and K.-I. Shimizu, Catal. Sci. Technol., 2014, 4, 3227-3234.

36 M. A. Hengne, N. S. Biradar and C. V. Rode, Catal. Lett., 2012, 142, 779-787. 